\title{
A PROSPECTIVE STUDY TO COMPARE INSULIN AND INSULIN ANALOGS IN TYPE II DIABETIC PATIENTS
}

\author{
GIREESHA KS ${ }^{1}$, SUMITHRA M ${ }^{2}$ \\ ${ }^{1}$ Department of Pharmacy Practice, Vels School of Pharmaceutical Sciences, Vels University, Chennai - 600 117, Tamil Nadu, India. \\ ${ }^{2}$ Department of Pharmaceutical Analysis, School of Pharmaceutical Sciences, Vels University, Chennai, Tamil Nadu, India. \\ Email: gireeshaks123@gmail.com
}

Received: 21 March 2017, Revised and Accepted: 19 April 2017

ABSTRACT

Objective: To compare the safety and quality of life of insulin and insulin analogues in Type II Diabetic patients.

Methods: 100 patients who are diagnosed with type - II diabetes milletus are taken.In these 50 patients are of insulin analogues and 50 patients are of conventional insulin The safety was based on number of hypoglycemic events.Data was collected by using the EQ-5D questionnaire and EQ Visual Analogue scale (EQ-VAS) to assess the quality of life from the patient.

Result:The percentage of the patients who had hypoglycemic events in conventional insulin group is $54 \%$ ( $\mathrm{n}=27$ ) and insulin analogues group is $20 \%$ $(n=10)$. Mean score points of QOL obtained by conventional insulin patients is 75.9 and by insulin analogues patients is 93.75

Conclusion: Insulin analogues group has low risk of hypoglycaemia when compared with the conventional insulin.The patient group who are in No problem category are found to have better QOL. The safety and QOL statistical differences constitute less likely among insulin and insulin analogues. The use of insulin analogues will continue to advance our efforts at improving diabetes care and treated related adverse outcomes can be reduced.

Keywords: Quality of life, Safety, Insulin analogs, Conventional insulin, Hypoglycemia.

(C) 2017 The Authors. Published by Innovare Academic Sciences Pvt Ltd. This is an open access article under the CC BY license (http://creativecommons. org/licenses/by/4. 0/) DOI: http://dx.doi.org/10.22159/ajpcr.2017.v10i7.18479

\section{INTRODUCTION}

Diabetes mellitus is a metabolic disorder which is expected to persist as a most important health problem owing to its severe complications. Insulin is indicated for type 1 diabetes patients and for patients with type 2 diabetes if glycemic control cannot be achieved satisfactorily in the course of oral hypoglycemic therapy [1]. Insulin is a poly peptide hormone produced by the beta cells of the pancreatic islets. It regulate the metabolism of carbohydrate, fats and protein by promoting the absorption of, especially glucose from the blood into fat, liver and skeletal muscle cells [2]. Insulin is differentiated into conventional insulin agents and insulin analogues. Conventional insulin agents are therapeutic regimen for treatment of diabetes mellitus which contracts with the newer intensive insulinotherapy.

Human insulin and Intermediate acting neutral protamine hagedron insulin (NPH) are the types of conventional insulin agents. There is a variation in the insulin absorption with the basal formulations such as NPH due to their low and relatively constant levels between meals [3]. Insulin analogues is an altered form of human insulin. Rapid- acting insulin such as insulin lispro (Eli Lilly), insulin as part (Novo Nordisk), are most commonly used for controlling post prandial hyperglycemia.Long acting insulin analogues have more physiologic substitution than NPH glycemic control [4]. Analogues have low risk of hypoglycemia with long duration of action and have a greater consistency than NPH [5]. Insulin analogues have more benefit in administration compared with human insulinsx [6]. Hypoglycemia is the most common side effect that may occur during insulin therapy. Symptoms of hypoglycemia includes: confusion, nausea, hunger, tiredness, perspiration, headache, heart palpitations, and numbness, around the mouth, tingling in the fingers, tremors, muscle weakness, blurred vision., lipodystrophy. Therapy with the insulin analogues provides better glycemic control and have low risk of hypoglycaemia.
Lispro, shows better quality of life in most of the patients [8] switching from the human insulin to insulin analogues there was a significant decrease in hypoglycaemic episodes accompanied by a significant increase in treatment satisfaction [10] health related quality of life is increased when insulin therapy is beginning with or switching to insulin analogue [11]

\section{METHODS}

Objective

To compare the safety and QOL of insulin and insulin analogs in Type II diabetic patients.

\section{Study design}

A prospective observational study was conducted over a period of 6 months. The data were collected from the patient's case sheet, drug chart, and also through direct patient interview.

\section{Study procedure}

Patient inclusion criteria

- A total of 100 patients who are diagnosed with Type II DM are included.

- Patients who are hospitalized (inpatients and outpatients) of general medicine department.

- Patients with other comorbid conditions such as hypertension, cardiovascular disease, and diabetic nephropathy.

\section{Patient exclusion criteria}

- Patients who were not willing to give informed consent.

- Patient with gestational diabetes and lactating mothers.

- The patient who do not wish to complete the questionnaire and those with cognitive impairment and visual or hearing loss. 


\section{Methodology}

- One hundred patients who are diagnosed with Type II DM are taken.

- In these, 50 patients are of insulin analogs and 50 patients are of conventional insulin.

- The safety was based on the number of hypoglycemic events.

- Data were collected using the EQ-5D questionnaire and EQ visual analog scale (EQ-VAS) to assess the QOL from the patient.

- The patients were examined on a structured questionnaire after their verbal consent.

- The EQ-5D questionnaire consists of mainly 5 dimensions:

- Mobility

- Self-care

- Usual activities

- Pain/discomfort

- Anxiety/depression.

- Each characteristic has mainly three levels which describe "no problem," "some problem," and "severe problem," and then patients were asked to designate about his/her health state by ticking in the box against the most suitable statement in each of the 5 dimensions.

- The EQ-5D levels were divided into "no problems" (level 1) and "some problems" (level 2) and "severe problem" (level3) visual analog scale is used to say how good or bad of patient health state.

- The patients were asked to draw a line from the box below to whichever point on the scale specifies their current health state.

- The EQ-5D questionnaire and EQ visual analog scale (EQ-VAS) scores are anchored on $100=$ best imaginable health and $0=$ worst imaginable health of the patient.

\section{Data Analysis}

The data were examined using GraphPad Prism software, Fisher's exact test, Microsoft XL, and T-test are used to determine the safety, and QOL between conventional insulin and insulin analog patients. The $\mathrm{p}<0.05$ is considered statistically significant.

\section{RESULT}

Among 100 study patients, 50 patients were on conventional insulin and 50 patients were on insulin analogs. The percentage of the patients who had hypoglycemic events in conventional insulin group is 54\% $(n=27)$ and insulin analogs group is $20 \%(n=10)$. The percentage of the patients who never had hypoglycemic events in conventional insulin group is $46 \%(n=23)$ and in insulin analog group is $80 \%(n=40)$ individually. The possibility of hypoglycemia has been calculated using Fisher's exact test (Table 1 and Fig. 1a, b).

Characteristics of the subjects based on EQ-5D questionnaire consist of mainly five dimensions such as mobility, self-care, usual activities, pain/ discomfort, and anxiety/depression. The grade given was described "no problem, and "problem." Data are analyzed using GraphPad Prism software, Fisher's exact test, T-test, for differentiation (Table 2 and Fig. 2a, b).

Comorbidity of the conventional insulin in the study population $(n=50)$ included 15 patients (30\%) with hypertension, 7 patients $(14 \%)$ with cardiovascular disease, 3 patients $(6 \%)$ with renal disease, 2 patients (4\%) with anemia, 5 patients $(10 \%)$ with thyroid disorder, 4 patients $(8 \%)$ with gastrointestinal disease, 2 patients $(4 \%)$ with diabetic nephropathy, 2 patients (4\%) with joint disorders, 5 patients $(10 \%)$ with respiratory disorders, and 5 patients $(10 \%)$ with no comorbidity. Comorbidity is estimated using the percentage of comorbidity patients in conventional insulin (Table 3 and Fig. 3).

Comorbidity of the insulin analogs in the study population $(n=50)$ included 10 patients (20\%) with hypertension, 7 patients $(14 \%)$ with cardiovascular disease, 2 patients (4\%) with renal disease, 1 patients (2\%) with anemia, 10 patients $(20 \%)$ with thyroid disorder, 5 patients $(10 \%)$ with gastrointestinal disease, 2 patients $(4 \%)$ with joint disorders, 3 patients $(6 \%)$ with respiratory disorders, and 10 patients $(20 \%)$ with no comorbidity. Comorbidity is estimated using the percentage of comorbidity patients in insulin analogs (Table 4 and Fig. 4).

The QOL of insulin and insulin analogs was evaluated based on the EQ5D VAS was given from the range of $0-100$, in which $0=$ worst imaginable health status of the patient and 100=best imaginable health status of the patient and the mean score points obtained by conventional insulin patients is 75.9 and by insulin analogs patients is 93.75 (Table 5 and Fig. 5).

\section{DISCUSSION}

A study conducted by Singh et al. [4] reported that therapy with the insulin analogs offers few clinical advantages over conventional insulins in the management of most patients with Type II diabetes. Although the evidence supporting the benefit of insulin analogs in terms of hypoglycemia is weak, these agents may be an option for patients with problematic hypoglycemia despite optimization of conventional insulin therapy.

Our results indicate that difference between the conventional insulin and insulin analogs is minimum in treatment of Type II DM.

A study conducted by Zinman [6] suggests that long-acting insulin analogs provide relatively peakless and more physiologic insulin replacement therapy than neutral protamine Hagedorn insulin. New basal insulin analogs have been developed with superior pharmacokinetic and pharmacodynamics properties; insulin degludec and a PEGylated insulin lispro. These agents are generally well tolerated and have been evaluated in Type II diabetes. In general rates of hypoglycemia in these trials were low, glucose control was comparable to currently available basal insulin analogs, and rates of nocturnal hypoglycemia were significantly and substantially lower.

Insulin analogs have statistically significant advantages for hypoglycemic events in Type II diabetic patients for nocturnal hypoglycemia; the results were not constant across NPH insulins.

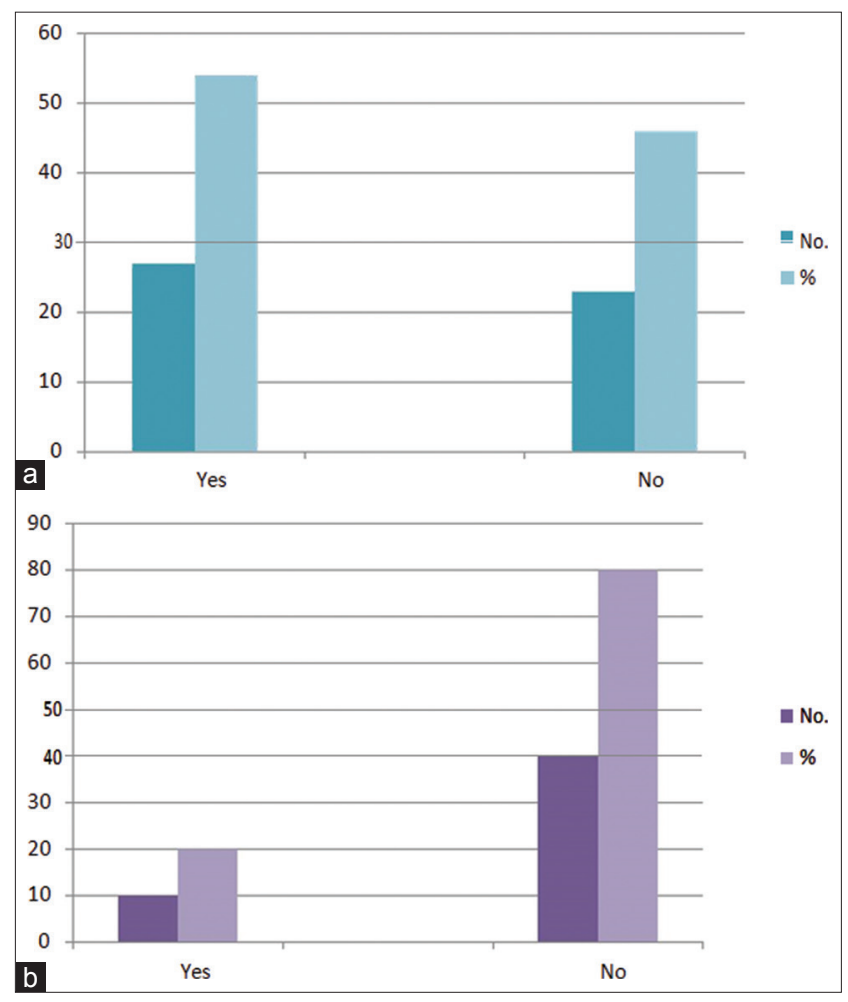

Fig. 1: (a) Safety level of hypoglycemic events in insulin patients. (b) Safety level of hypoglycemic events in insulin analogs patients 
Table 1: Impact of therapy between insulin and insulin analogs on safety level

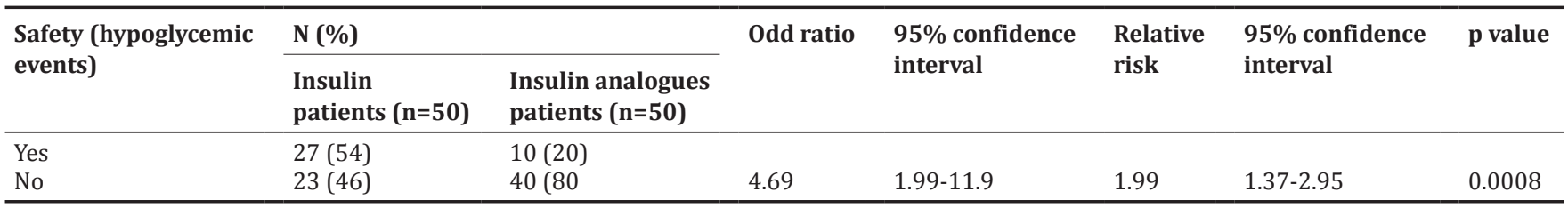

Table 2: Characteristics of the subjects based on EQ-5D questionnaire

\begin{tabular}{|c|c|c|c|c|c|c|c|c|c|c|}
\hline \multirow[t]{2}{*}{ S. No. } & \multirow[t]{2}{*}{ Variable } & \multicolumn{2}{|c|}{$\begin{array}{l}\text { Insulin } \\
\text { patients }(n=50)\end{array}$} & \multicolumn{2}{|c|}{$\begin{array}{l}\text { Insulin analogues } \\
\text { patients }(n=50)\end{array}$} & \multirow[t]{2}{*}{ Odd ratio } & \multirow[t]{2}{*}{$\begin{array}{l}95 \% \text { confidence } \\
\text { interval }\end{array}$} & \multirow[t]{2}{*}{$\begin{array}{l}\text { Relative } \\
\text { risk }\end{array}$} & \multirow[t]{2}{*}{$\begin{array}{l}95 \% \text { confidence } \\
\text { interval }\end{array}$} & \multirow[t]{2}{*}{$p$ value } \\
\hline & & Problem & $\begin{array}{l}\text { No } \\
\text { problem }\end{array}$ & Problem & $\begin{array}{l}\text { No } \\
\text { problem }\end{array}$ & & & & & \\
\hline 1. & Mobility & 13 & 37 & 7 & 43 & 0.46 & $0.18-1.28$ & 0.71 & $0.49-1.12$ & 0.21 \\
\hline 2. & Selfcare & 15 & 35 & 10 & 40 & 0.58 & $0.22-1.43$ & 0.77 & $0.53-1.21$ & 0.35 \\
\hline 3. & Usual activity & 27 & 23 & 17 & 33 & 0.43 & $0.19-1$ & 0.66 & $0.44-0.98$ & 0.0693 \\
\hline 4. & Pain & 15 & 35 & 12 & 38 & 0.73 & $0.31-1.85$ & 0.86 & $0.58-1.35$ & 0.65 \\
\hline 5. & Anxiety & 25 & 25 & 10 & 40 & 0.25 & $0.09-0.59$ & 0.53 & $0.36-0.78$ & 0.0031 \\
\hline
\end{tabular}

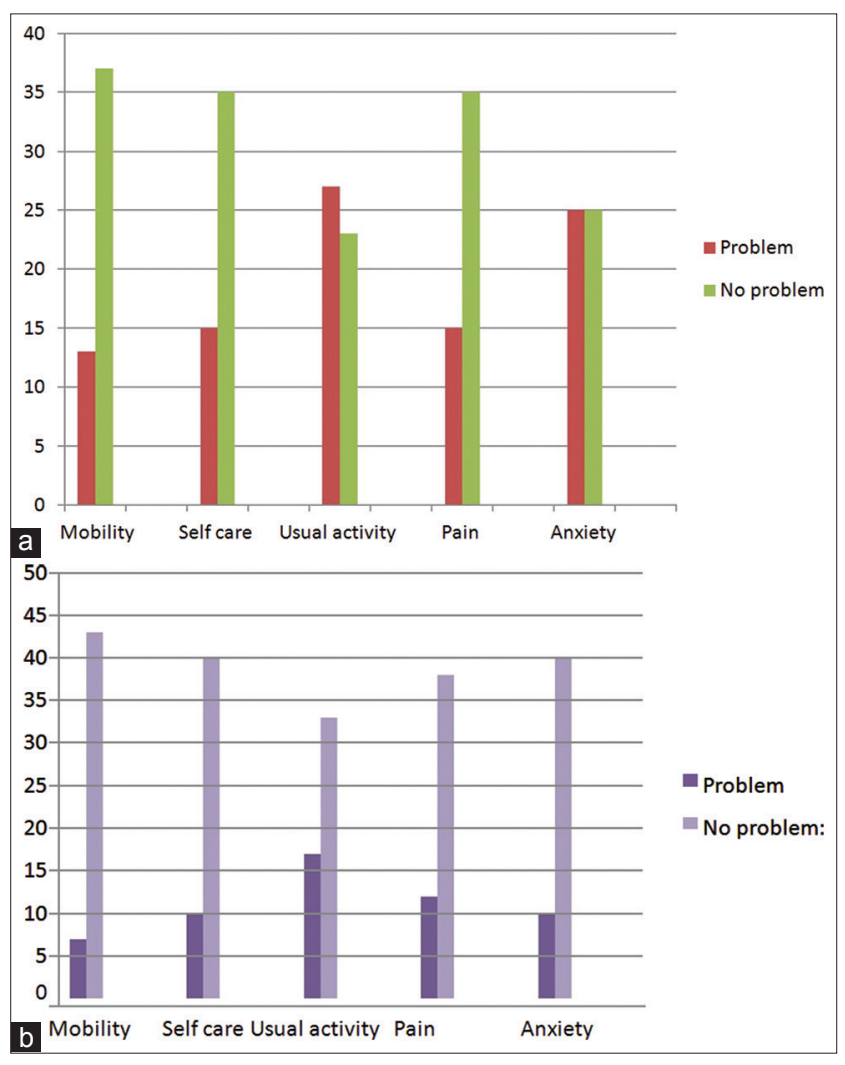

Fig. 2: (a) Characteristics of insulin patients based on EQ-fivedimensional (5D) questionnaire. (b) Characteristics of insulin analogs patients based on EQ-5D questionnaire

A study conducted by Shah et al. [7] estimated that by comparing with the EQ-VAS scores, beginning or changing insulin associated with a significant increase in health-related QOL (HRQOL).

HRQOL reported that increased statistically significant in people administering any insulin analog regimen and across all regions although there were some marked regional differences in reported HRQOL at baseline. This study suggests that analogs had its own capability in increasing the QOL. In similarity to this literature, our study suggests that there is no significant difference in QOL between conventional insulin and insulin analogs. The overall percentage of QOL found on 5 dimensions was more for analog group (75.9\%) than the conventional group (93.75\%).

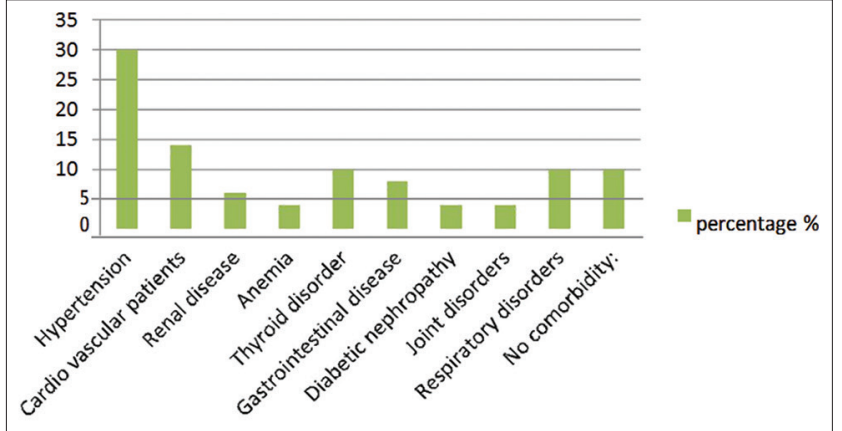

Fig. 3: Distribution based on insulin comorbidity

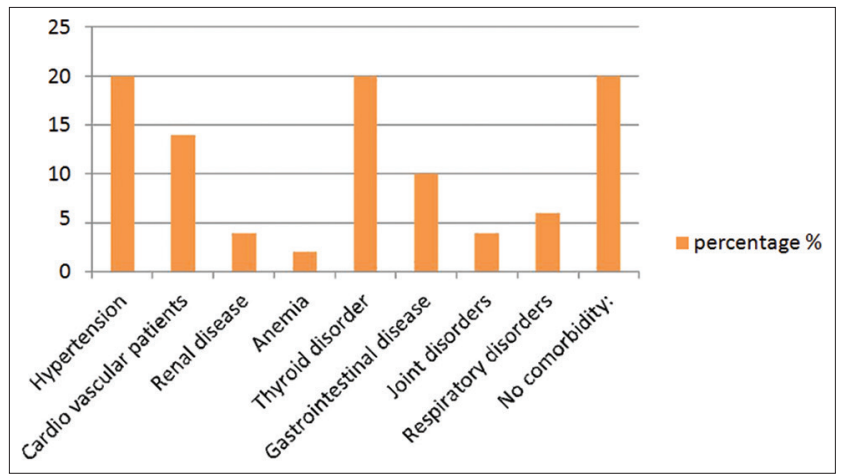

Fig. 4: Distribution based on insulin analogs comorbidity

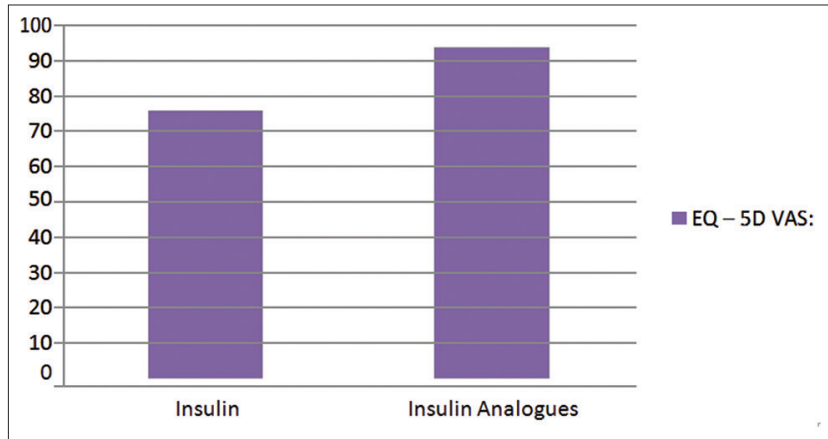

Fig. 5: EQ-five-dimensional visual analog scale (quality of life) 
Table 3: Comorbidity of insulin in study population

\begin{tabular}{lll}
\hline S.No. & Comorbidity & $\begin{array}{l}\text { Number of patients in insulin } \\
\mathbf{n = 5 0}(\%)\end{array}$ \\
\hline 1. & Hypertension & $15(30)$ \\
2. & Cardio vascular patients & $7(14)$ \\
3. & Renal disease & $3(6)$ \\
4. & Anemia & $2(4)$ \\
5. & Thyroid disorder & $5(10)$ \\
6. & Gastrointestinal disease & $4(8)$ \\
7. & Diabetic nephropathy & $2(4)$ \\
8. & Joint disorders & $2(4)$ \\
9. & Respiratory disorders & $5(10)$ \\
10. & No comorbidity & $5(10)$ \\
\hline
\end{tabular}

Table 4: Comorbidity of insulin analogs in study population

\begin{tabular}{lll}
\hline S.No. & Comorbidity & $\begin{array}{l}\text { Number of patients in insulin } \\
\text { analogs } \mathbf{n = 5 0} \mathbf{5 \%})\end{array}$ \\
\hline 1. & Hypertension & $10(20)$ \\
2. & Cardio vascular patients & $7(14)$ \\
3. & Renal disease & $2(4)$ \\
4. & Anemia & $1(2)$ \\
5. & Thyroid disorder & $10(20)$ \\
6. & Gastrointestinal disease & $5(10)$ \\
7. & Joint disorders & $2(4)$ \\
8. & Respiratory disorders & $3(6)$ \\
9. & No comorbidity & $10(20)$ \\
\hline
\end{tabular}

Table 5: Comparison of quality of life between insulin and insulin analogs

\begin{tabular}{lll}
\hline S.No. & Types & EQ-5D VAS \\
\hline 1. & Insulin & 75.9 \\
2. & Insulin analogs & 93.75 \\
\hline
\end{tabular}

5D: Five-dimensional, VAS: Visual analog scale

\section{CONCLUSION}

The safety among insulin analogs and conventional insulin is being studied. Insulin analogs group has a low risk of hypoglycemia when compared with the conventional insulin. The QOL was determined based on EQ-VAS. The patient groups who are in no problem category are found to have better QOL. The safety and QOL statistical differences constitute less likely among insulin and insulin analogs. The use of insulin analogs will continue to advance our efforts at improving diabetes care and treated related adverse outcomes can be reduced.

\section{REFERENCES}

1. Jasvinder SB, Gurjit KB, Amit J, Seema R, Mastana SS, Ralhan SK, et al. Identification of risk factors for the high prevalence of type $2 \mathrm{DM}$ and its complications in a Punjabi population. Int J Diabetes Dev Ctries 2007;27(4):108-15.

2. De Fronzo RA. From the triumvirate to the omnious octet: A new paradigm for the treatment of Type 2 diabetes mellitus. Diabetes 2009;58:773-87.

3. Nyenwe EA, Jerkins TW, Umpierrez GE, Kitabchi AE. Management of type 2 diabetes: Evolving strategies for the treatment of patients with type 2 diabetes. Metabolism 2011;60(1):1-23.

4. Singh SR, Ahmad F, Lal A, Yu C, Bai Z, Bennett H. Efficacy and safety of insulin analogues for the management of diabetes mellitus: A metaanalysis. CMAJ 2009;180(4):385-97.

5. Rolla A. Pharmacokinetic and pharmacodynamic advantages of insulin analogues and premixed insulin analogues over human insulins: Impact on efficacy and safety. Am J Med 2008;121 6 Suppl: S9-19.

6. Zinman B. Newer insulin analogs: Advances in basal insulin replacement. Diabetes Obes Metab 2013;15 Suppl 1:6-10.

7. Shah S, Zilov A, Malek R, Soewondo P, Bech O, Litwak L. Improvements in quality of life associated with insulin analogue therapies in people with type 2 diabetes: Results from the A1chieve observational study. Diabetes Res Clin Pract 2011;94(3):364-70.

8. Beverley B, Eschwege E. The diagnosis and classification of diabetes and impaired glucose tolerance. In: Pickup JC, Williams G, editor. Textbook of Diabetes and Impaired Glucose Tolerance. $3^{\text {rd }}$ ed., Ch. 2. Oxford: Blackwell Science; 2003. p. 2.1-2.10.

9. Dipiro JT. Pharmacotherapy Handbook. $7^{\text {th }}$ ed. New York: McGraw-Hill; 2009. p. 210-1, 649, 651-3.

10. Khardori R. Type 2 Diabetes Mellitus Differential Diagnoses Medscape; 2014.

11. Gomez-Perez FJ, Aguilar-Salinas CA, Almeda-Valdes P, Cuevas-Ramos D, Lerman Garber I, Rull JA. HbA1c for the diagnosis of diabetes mellitus in a developing country. A position article. Arch Med Res 2010;41(4):302-8.

12. Nicholas AB. Davidson Principles and Practice of Medicine. $22^{\text {nd }}$ ed. Ch. 21. UK: Elsevier Health; 2014. p. 801.

13. Tirupathi KD. Classification of Pharmacology. $7^{\text {th }}$ ed. New Delhi: Jaypee; 2006

14. Indian Diabetes Federation. Available from: http://www.idf.org. 